\title{
Psicanálise e marxismo: a fratura da Associação Psicanalítica Argentina (1971)
}

Hugo Vezzetti

Tradução de Fernando Antonio Pinheiro Filho

Marie Langer testemunhava o encontro da psicanálise com a política no cenário de radicalização aberto na Argentina em 1969: "Como instituição, fomos despertos pelo 'Cordobazo”" (Langer, 1971, p. 17). Dizia-o para dar conta da ruptura da Associação Psicanalítica Argentina (APA) em 1971. Como apresentar a trama de relações que enlaçam uma revolta operária e estudantil com a crise na organização oficial da psicanálise? De início, para evitar alguns equívocos, a radicalização dos psicanalistas não começa (não poderia ter começado) no espaço recôndito da instituição, nem tampouco, como se verá, na "rua".

A APA havia sido criada em 1942 por um pequeno círculo de médicos profundamente interessados na obra de Freud a partir de uma perspectiva clínica e terapêutica. Entre eles destacava-se Ángel Garma, emigrado espanhol, que fizera sua formação psicanalítica na Alemanha e era membro da Associação Psicanalítica Internacional (IPA, na sigla em inglês). No grupo inicial estavam também duas figuras que cumpriram o papel mais destacado no deslocamento da disciplina freudiana do campo médico: Enrique Pichon Rivière, no domínio da psiquiatria em suas relaçôes com a psicologia, e Arnaldo Rascovsky, no âmbito da pediatria e da clínica de crianças. Marie Langer, emigrada vienense, e Celes Cárcamo, um argentino que havia se formado em Paris, completavam o círculo original. A nova associação foi imediatamente reconhecida por Ernest Jones, então presidente da IPA, 
1. Para uma apresentação histórica da APA, ver Plotkin (2003, cap. 2). ainda que devesse esperar o Congresso Internacional de Zurich, em 1949, o primeiro realizado depois da guerra, para alcançar um reconhecimento definitivo. Foi a primeira associação psicanalítica latino-americana admitida na organização e sua Revista de Psicoanálisis, criada em 1943, foi a primeira publicação periódica da disciplina em língua castelhana ${ }^{1}$.

A imagem que oferecia Marie Langer em 1971, de um súbito descobrimento da política nas imagens das lutas em Córdoba, não tem correspondência com um processo que havia começado antes e que teve atores, espaços e tópicos precisos. Mas, certamente, essa irrupção crua do poder alterava uma das bases sobre as quais a entidade dos psicanalistas havia assentado seu funcionamento institucional: a "neutralidade" (uma categoria própria da cura) entendida como abstinência política e transferida para as relações com os problemas da esfera pública. A APA havia nascido como uma entidade que propunha, seguindo o modelo da IPA e o comando de Freud, nuclear e ao mesmo tempo certificar os praticantes da disciplina. Havia alcançado certa consolidação e um moderado crescimento durante o primeiro peronismo, a partir, sobretudo, das relaçôes com o dispositivo médico e psiquiátrico. Um primeiro mercado de pacientes desenvolvera-se pela própria dinâmica da formação (que obrigava os candidatos a começar sua análise) e pelas recomendações dos iniciados nessa experiência. Um traço dominante, quiçá uma condição, dessa primeira implantação, até os anos de 1960, havia sido a omissão de qualquer pronunciamento sobre a cena política e os problemas da sociedade.

$\mathrm{Na}$ verdade, o ideal de um movimento apolítico tinha uma ampla tradição na corporação freudiana e era manifesto na Alemanha desde o período de ascensão do nazismo. A Sociedade Psicanalítica Alemã tratara de evitar seu fechamento mediante uma série de concessões às autoridades: em 1933, negociou a expulsão de Wilhelm Reich, um comunista perseguido pelo regime; em 1936, aceitou ingressar no Instituto Alemão para a Investigação Psicológica e a Psicoterapia (conhecido como o Instituto Göring, porque seu diretor era Mathias Heinrich Göring, primo de Hermann Göring) e para isso impôs a renúncia "voluntária” dos membros judeus. Ernest Jones, não judeu, de Londres, estava a cargo dessa negociação. Apesar de todos os esforços feitos para distanciar-se dos estereótipos da "ciência judaica" ou materialista, incluindo os esforços de alguns psicanalistas alemães para mostrar que os descobrimentos freudianos (sobretudo na psicoterapia e na clínica) eram compatíveis com os dogmas do hitlerismo, a Sociedade Psicanalítica Alemã foi fechada em 1938. Mesmo assim, o molde ideológico da abstenção diante dos 
tópicos da política pública permaneceu inalterado. O mesmo Jones o expressava triunfalmente em 1949, depois da guerra: "Há uma tentação muito compreensível que busca agregar os fatores sociopolíticos aos fatores que nos concernem diretamente e reler nossos descobrimentos em termos sociológicos; é possível observar com orgulho que tal tentação, com escassas exceções, foi evitada com determinação" (apud Nitzschke, 2003, pp. 98-108).

Nesse ponto cego da empresa psicanalítica não só se reprimia a militância ou os pronunciamentos sobre acontecimentos públicos, mas também se esfumaçava a possibilidade de uma livre discussão com as correntes do pensamento filosófico e político, no nível de conceitos e problemas que não eram alheios aos efeitos produzidos pela obra de Freud. Na Argentina, a APA ajustava-se ao modelo e configurava-se como uma bolha separada e alheia ao campo político sob o primeiro peronismo, que se havia mostrado muito pouco acolhedor das ideias freudianas tanto na universidade como no dispositivo psiquiátrico. Indubitavelmente, a maioria das primeiras figuras da psicanálise compartilhava uma opinião de oposição, que era a das classes médias intelectuais, mas a instituição não se pronunciava sobre programas ou medidas de governo.

Marie Langer oferece um bom exemplo dessa autocensura com a discussão e a publicação de seu trabalho sobre "o mito do menino assado". O texto abordava uma história sinistra, que circulava em Buenos Aires nesses anos, sobre uma empregada que assassinava e assava um menino pequeno e o oferecia a seus pais. Foi publicado primeiro como artigo na Revista de Psicoanálisis em 1950, e com algumas poucas mudanças foi integrado a Maternidady sexo, o primeiro livro de Langer, em 1951. Nessas versôes, a publicação girava em torno das categorias kleinianas da "mãe má”. Numa reedição ampliada, em 1957, depois da queda de Perón, o texto agregava algo que havia sido omitido na primeira versão: a interpretação dos mitos maternos e a imagem da mãe devoradora chegava até a figura de Eva Perón. Essa ampliação da análise até uma dimensão política estivera presente na discussão realizada na APA, mas acabou censurada pela própria autora nas publicações realizadas, na revista e em livro, sob o primeiro peronismo ${ }^{2}$. O episódio é representativo da postura opositora ao peronismo do primeiro grupo psicanalítico e ao mesmo tempo mostra uma regra geral de silêncio nas expressões políticas públicas, mesmo nos casos em que poderiam aparecer atenuadas, subentendidas ou revestidas de uma linguagem técnica ou um distanciamento de especialistas. Nada mudou na instituição com a queda de Perón, em 1955 ou já avançados os anos de 1960. A versão final do texto de Langer ou o
2. Ver Langer (1950, 1951, 1957). Para uma leitura mais detida do texto, ver Vezzetti (1995). 
apêndice que incluía as referências polêmicas sobre Eva Perón não foram publicados na revista da APA, mas numa das editoras nascidas nesses anos. O mesmo se dava com os trabalhos de psicanalistas como Enrique Pichon Rivière ou José Bleger quando excediam o repertório restrito dos temas da disciplina. Mas em 1966 o golpe do general Onganía é mencionado na revista da APA como a "mudança de circunstância" que obrigava a mudar a sede de um congresso convocado com anterioridade (cf. Carpintero e Vainer, 2004).

Em poucos anos, de 1966 ao final da década, cai essa denegação da política, ao menos para alguns, e tem lugar uma escalada de radicalização que chega à ruptura e estende seus efeitos a esse círculo psicanalítico cada vez mais em contato com a agitação contestatória que percorria a sociedade. Emilio Rodrigué, presidente da APA em 1966 e um dos renunciantes, chamou retrospectivamente de "jaula dourada" a esse fechamento defensivo nos rituais, nas hierarquias e nas prerrogativas da organização (cf. Rodrigué, 2000). A jaula não se abriu de súbito e no acontecimento crítico, dramático, recortado no tempo, se condensavam processos mais amplos e se superpunham diversas crises.

\section{0 acontecimento}

A crise na APA precipitou-se em novembro de 1971, com a renúncia de dois grupos, Plataforma, primeiro, e Documento, depois. Cuestionamos, a compilação realizada por Marie Langer, apareceu nesse mesmo mês de novembro. É evidente que havia sido preparada antes das renúncias: o prólogo de Langer não as menciona e está datado de outubro de 1971, mas já antecipava a ruptura. A fratura pública era o desenlace de um processo prévio de conflitos, que teve entre suas condições mais gerais a acelerada radicalização política da sociedade, sobretudo das camadas intelectuais e profissionais. Mas, além disso, seus conteúdos e seus estilos mostravam a imbricação de zonas do discurso psicanalítico com uma cultura intelectual de esquerda que estava num momento de aguda transformação no plano das ideias e das organizações. Esse processo abarcava franjas importantes de um peronismo radicalizado, com base na juventude (a JP ou "tendência revolucionária") e com uma adesão muito ampla nos meios universitários. $\mathrm{O}$ perfil ideológico do que nesses anos começou a chamar-se de "nova esquerda" (castrista, guevarista, maoísta etc.), e que abrangia o novo peronismo juvenil, se afirmava na separação, ao menos, ou na ruptura aberta, com as tradições do Partido 
Comunista e do Partido Socialista. Era a mesma configuração política e cultural de que dá conta Oscar Terán quando recorda sua adesão, antes a um "partido cubano" que a uma organização definida, que sustentava a certeza da via revolucionária ${ }^{3}$.

Plataforma, o grupo mais politizado e que abriu o caminho, havia nascido antes, como parte da Plataforma Internacional, um núcleo dissidente dentro da IPA, surgido em Roma, em 1969, por ocasiāo do XX Congresso Internacional. Em suas declaraçôes, vangloriava-se de ter sido "o primeiro do mundo que se desgarra de uma associação psicanalítica por razões político-ideológicas" (Plataforma, 1972, p. 8). Com efeito, pelo número e qualidade dos renunciantes (que incluía uma das fundadoras, Marie Langer, um ex-presidente, Emilio Rodrigué, e quatro didatas - Diego e Gilou García Reinoso, além de Langer e Rodrigué) e pelos motivos esgrimidos, não havia antecedentes de uma ruptura semelhante na história do movimento psicanalítico internacional.

As razões esgrimidas acentuavam a justificação política:

Como cientistas e profissionais temos o propósito de colocar nossos conhecimentos a serviço das ideologias que questionam sem concessōes o sistema que em nosso país se caracteriza por favorecer a exploração das classes oprimidas, por entregar as riquezas nacionais aos grandes monopólios e por reprimir toda manifestação política que tenda a rebelar-se contra ele. Pronunciamo-nos, pelo contrário, comprometendo-nos com todos os setores combativos da população que, no processo de libertação nacional, lutam pelo advento de uma pátria socialista.

Ainda que questionasse a estrutura hierárquica e o elitismo da instituição, a declaração era definitiva no rechaço do reformismo: "queremos que fique claro que não nos impulsiona grupal ou individualmente nenhuma intenção mais ou menos reformista nem reivindicatória intrainstitucional”.

O outro grupo, Documento, propunha uma dissidência mais apegada à crítica da instituição, ao menos inicialmente. Fernando Ulloa, uma das figuras destacadas do grupo, era diretor do Centro Racker (de "extensão" e assistência externa da instituição) e havia tentado mudanças que foram bloqueadas pela direção. As diferenças internas agudizaram-se e circularam em documentos que se trocavam com a Comissão Diretora, até chegar à renúncia pública, em parte precipitada pela ruptura prévia do grupo Plataforma.

Em sua declaração pública, Documento impugnava a APA como "uma empresa que luta pela posse monopolista da psicanálise" e que participava
3. Ver "Entre la filosofía y la historia: un recorrido", entrevista realizada em 1994 por Javier Trímboli e Roy Hora, em Terán (2006, pp. 17-18). 
de um "sistema de privilégios". Inicialmente, assim, a crítica se focava na "estrutura interna, em que um reduzido número de pessoas detém, formalmente e de fato, a totalidade do poder político", e continuava com a denúncia da "instrumentação ideológica da psicanálise a serviço das classes dominantes de nossa sociedade". Finalmente, terminava também, como Plataforma, situando a decisão no horizonte político de uma mudança na sociedade: "nossa ruptura com a APA aponta para o fortalecimento do amplo movimento integrado por indivíduos e grupos que, para além das diferenças táticas circunstanciais, tendem ao resgate da psicanálise, pondo-a a serviço de uma meta partilhada: o advento de uma Sociedade Socialista" (Documento, 1972, p. 6).

O grupo Documento aparecia como mais moderado, sobretudo ante a visão radicalizada de Plataforma, que se assumia como uma vanguarda destinada a acelerar e aprofundar os conflitos e que não só não fez nada para incorporar os outros, mas precipitou a ruptura para ser o primeiro. $\mathrm{Na}$ exposição de motivos que acompanhava a renúncia, não falta a impugnação crítica da instituição: elitismo e conformismo, estancamento na formação e ritualismo na leitura de Freud, fechamento autocomplacente e isolamento do campo social, submissão econômica. Nesse sentido, é notável o texto que Fernando Ulloa dedicava à análise da instituição para mostrar como entre o enquadramento terapêutico e a ordem hierárquica se estabelecia uma relação de causalidade recíproca que alimentava o autoritarismo, a intolerância à inovação e a paralisação do conhecimento (cf. Ulloa, 1971, p. 109). Esse trabalho destaca-se, ademais, por ser praticamente o único publicado em Cuestionamos que não se obriga a introduzir explicitamente o contexto extrainstitucional das lutas sociais e políticas.

$\mathrm{Na}$ verdade, em ambos grupos encarnavam-se críticas e buscas nascidas nos anos anteriores, fora da APA, e que tinham forjado uma tradição inovadora por meio, sobretudo, das obras de Pinchon Rivière e Bleguer. Com a ruptura entravam em jogo também a dimensão teórica e as modalidades de formação em psicanálise. Na APA denunciava-se uma concepção burocrática, fechada à relação da psicanálise com outras disciplinas, em especial com as ciências sociais, e às inovações práticas, para além do dispositivo estabelecido em torno do divã. E a projeção do discurso psicanalítico para fora da organização corporativa ligava-se a uma atitude radicalmente aberta de extensão e ensino. $\mathrm{Na}$ medida em que uma das impugnaçóes rechaçava a pretensão do monopólio formativo por parte da APA, um eixo da ação dos renunciantes devia dirigir-se à construção de centros de ensino projeta- 
dos como uma alternativa integral (teórica, política, institucional e pedagógica) ao que deixavam: tal foi o objetivo do Centro de Docência e Investigação, que se converteu em objeto de uma luta entre os dois grupos, finalmente resolvida a favor de Documento.

Plataforma propunha-se a permanecer como um grupo sustentado por acordos políticos (ainda que as contradições internas estalassem imediatamente), enquanto Documento não tinha um projeto que ultrapassasse a decisão de separar-se da instituição oficial. Mas os laços entre os dois grupos eram estreitos no plano da psicanálise. Finalmente, as declaraçōes de ruptura de Plataforma e Documento coincidem em projetar sua ação para além da instituição e no propósito de uma verdadeira refundação da psicanálise na via de uma revolução socialista ${ }^{4}$. A entidade psicanalítica passava a ser secundária diante do compromisso político: na medida em que a direção fundamental do movimento se orientava para fora, em direção a um cenário de lutas na sociedade, os pronunciamentos não se colocavam a necessidade de um debate sobre as funções mais específicas de uma instituição psicanalítica, a partir não das características da instituição que acabavam de abandonar, mas dos termos em que o próprio Freud havia estabelecido o problema.

No caso de Plataforma, a vontade de compromisso político tornou-se a maior fonte de conflitos, na medida em que, desde 1972, a cena pública esteve dominada pelo processo que culminou com as eleições de 1973 e o triunfo do peronismo: as contradições e alinhamentos diversos entre a filiação ao peronismo revolucionário e as diferentes opções das esquerdas terminou levando o grupo à dissolução. Mas os conflitos estavam presentes desde o momento da ruptura. Em dezembro, a um mês da crise, soube-se da renúncia de Raúl Sciarreta ao grupo. Sciarreta era um intelectual de esquerda, ligado ao PC até meados dos anos de 1960 e introdutor da renovação althusseriana do marxismo; vários dos renunciantes haviam passado por seus grupos de estudo5. Em sua renúncia pública denunciava "um setor de Plataforma" que teria pretendido impor um programa de atividades sem uma discussão prévia. $\mathrm{O}$ ponto da disputa era a criação de um centro de docência, aberto a psiquiatras e psicólogos, no marco do projeto de uma Coordenadoria de Trabalhadores de Saúde Mental: o objeto da disputa eram os lineamentos políticos e a direção desse empreendimento, numa frente que terminou nucleando milhares de jovens profissionais, sobretudo psicólogos. Plataforma havia dado a conhecer um programa muito exaustivo (“programa onipotente", dizia Sciarreta) e era acusada de buscar uma posi-
4. Os termos são praticamente idênticos: Plataforma fala de uma "inscrição qualitativa e quantitativamente distinta dentro do processo social, econômico e político nacional e latino-americano", e do compromisso com a luta "pelo advento de uma pátria socialista”; Documento fala da "reinscrição da psicanálise em condições diferentes" e do "serviço [...] para o advento de uma sociedade socialista”. Ver Documento (1972, pp. 5 e 6-7).

5. Sobre a trajetória de Sciarreta, ver Tarcus (2007, pp. 616-617). 
6. R. Sciarreta, carta pública de 14 de dezembro de 1971, meu arquivo. Agradeço a Mariano Plotkin, que me disponibilizou esse material. ção hegemônica e sectária. Sciarreta não poupava qualificações para referirse ao grupo: "círculo de autodeclarados revolucionários", dizia, que pretendia impor "relaçôes de intolerância e superioridade" em relação ao outro grupo, indiferentes às lutas de candidatos que continuavam na APA brigando pelos mesmos objetivos que precipitaram a ruptura. "Sectarismo" e "populismo" ("que tacha de cientificismo toda discussão teórica, com a falácia de que a teoria só se produz na prática política”); termos que, para Sciarreta, se resumem a uma "ideologia infantil de esquerda".

\section{Genealogias}

No tempo curto da ruptura atuam processos mais amplos: em Buenos Aires, a crescente implantação da psicanálise na cultura intelectual, na universidade e nas instituições de saúde mental; no plano internacional, um movimento de contestação inédito que nasce na Europa (entre Genebra e Milão) e emerge no citado congresso internacional da IPA, em 1969.

Em Buenos Aires, até meados dos anos de 1960, a psicanálise já havia completado seu caminho de expansão e implantação na universidade e na cultura intelectual. $\mathrm{O}$ freudismo teve, em seu desempenho global, duas vias de implantação: médica, de um lado; intelectual e literária, de outro, e mostrou capacidade de apelo a dois públicos. Na cultura de Buenos Aires, uma primeira condição da crise de 1971 nasceu com essa ampliação que questionava a recepção puramente médica. É certo que a psicanálise se redefinia em direção aos problemas da saúde mental pública, nas novas experiências de inserção hospitalar, mas o fazia sobretudo na interação com os discursos que renovavam a filosofia e as ciências sociais no espaço universitário e no campo intelectual: sartrismo, marxismos, sociologia e antropologia, semiologias aplicadas a diversos objetos.

O deslocamento da psicanálise para a esfera pública, para fora da clausura da instituição, produziu-se, então, em dois âmbitos interconectados: a universidade (a Faculdade de Filosofia e Letras de Buenos Aires) e o dispositivo da saúde mental, sobretudo o Serviço de Psicopatologia do Hospital de Lanús, criado e dirigido por esses anos por Mauricio Goldenberg. Nesses dois espaços se processava uma reorientação da disciplina psicanalítica. Direta ou indiretamente, as ideias de Pichon Rivière e de Bleger inspiraram os projetos de reforma e modernização de um campo "psi” que interconectava psiquiatria, psicologia e psicanálise. Duas figuras muito ativas do grupo Plataforma na ruptura, que foram além disso os elos com o movimento 
internacional, Armando Bauleo e Hermán Kesselman, eram discípulos de Pichon e de Bleger. Bauleo era um médico psiquiatra que fazia sua formação na APA: era membro do PC como Bleger e trabalhava com ele na Faculdade de Filosofia e Letras, no curso de Psicologia. Kesselman, também psiquiatra e candidato na APA, foi um dos participantes mais ativos na experiência de transformação psiquiátrica e psicoterapêutica que se desenvolveu no Serviço de Goldenberg em Lanús; foi também docente no curso de Psicologia, numa matéria dirigida por Goldenberg. Neles, pode-se dizer, mostra-se esse cruzamento de figuras e de espaços públicos que estiveram entre as condições menos imediatas da crise de $1971^{7}$.

Bleger ocupava, na década de 1960, a posição de intelectual-farol de uma psicanálise crítica, aberta às tradiçôes intelectuais de esquerda, que buscava um horizonte social para o desenvolvimento da disciplina freudiana. Era um psicanalista da segunda geração, formado com Pichon Rivière; e era também, desde muito jovem, membro do PC, tendo implantado, sem muito êxito na instituição oficial, o debate sobre o encontro da psicanálise com o marxismo. Havia publicado Psiconálisis y dialéctica materialista, em 1958, uma obra que se propunha intervir criticamente a uma só vez na psicanálise e na cultura intelectual marxista, e que se inspirava na obra de juventude de Georges Politzer e em autores franceses que já haviam explorado essa aproximação. O livro teve um impacto evidente no âmbito do PC: foi discutido por psiquiatras comunistas e pelos papas intelectuais do partido; como consequência, Bleger foi afastado da organização até 1962; mas não teve nenhuma repercussão na instituição psicanalítica, que o ignorou (cf. Bleger, 1968b; Vezzetti, 1991; Dagfal, 2009).

Respeitado pelos mais velhos, Bleger fora o mestre de vários dos renunciantes mais jovens, sobretudo o duo formado por Kasselman e Bauleo. Havia proposto, no clima das ideias e da sensibilidade reformista do pósperonismo, uma ação renovadora que tivesse efeitos simultâneos mas diferenciados sobre o universo doutrinário do comunismo e sobre a disciplina freudiana. Não apontava para uma integração "freudo-marxista", mas para um tipo de fermento recíproco que respeitasse a autonomia dos domínios, o sujeito psíquico e a formação econômico-social. Mas em 1971 o clima das ideias havia mudado: à expansão da disciplina freudiana fora da APA agregava-se o fermento de uma radicalização política mobilizadora do campo intelectual e universitário. Marie Langer, no texto que se converteu no paradigma da ruptura, dizia outra coisa: a psicanálise mesma devia reconverter-se em ferramenta da transformação revolucionária da sociedade ${ }^{8}$.
7. Bauleo teve além disso uma participação muito importante na experiência de comunidade terapêutica desenvolvida, em fins de 1968 , num serviço do Hospital Alejandro Korn de Melchor Romero, o asilo psiquiátrico próximo a La Plata. Ver Chama (1999, p. 29).

8. Ver "Psicoanálisis y/o revolución social”, em Langer (1971, p. 268). 


\section{Freud e Marx}

9. Ver "Prólogo", em Langer (1971, pp. 14-15).

10. Idem, pp. 15-17.
Um dos problemas principais, senão o maior, da exploração desse encontro da psicanálise contestatória com a política produz-se à luz da integração ou da relação complementar entre Freud e Marx. Em princípio, o debate com Freud era necessário, e tratava-se de recuperar para a psicanálise uma função científica transformadora. E de fato esse debate esteve majoritariamente ausente. Havia mais de um Freud implicado nesse momento de comoção das tradições teóricas e de leitura de sua obra. Marie Langer, por exemplo, distinguia entre o "Freud cientista" e o "Freud ideológico". Mas quando especificava o cientista em Freud ("nos mostra como a ideologia dominante se transmite, por meio do superego, de geração em geração, e torna lerdo o homem em sua capacidade de mudança”), parece que é Marx (lido através de Althusser) o autor de referência ${ }^{9}$. É no marxismo, então, que se aninham as certezas a partir das quais a psicanálise devia ser recriada. $\mathrm{O}$ artigo de Langer, "Psicoanálisis y/o revolución social", levado ao Congresso de Viena de 1971, mostra que a decisão de não "renunciar" ao marxismo implicava a recuperação de uma identidade ideológica antes que a de uma ferramenta teórica.

Se a luta ideológica, de classes, impunha sua lógica implacável no espaço psicanalítico privado, sustentado pela transferência, como não ver ali a necessidade de uma reformulação de algumas teses freudianas fundamentais? Com efeito, nessa impugnação, o lugar de Freud não deixava de ser ambíguo. De um lado, era claro (como já dissera Bleger) que se devia rechaçar sua ideologia, própria de um burguês ilustrado; mas quanto à obra mesma e aos conceitos, quando Langer buscava as marcas revolucionárias da psicanálise, as referências saíam não do marco freudiano, mas do marxista, ou bem de Althusser, ou do freudismo reichiano, ainda que confessando ter lido Reich recentemente, no momento da ruptura ${ }^{10}$. Sabe-se que não houve no núcleo contestatório quem pudesse exibir um compromisso mais ou menos permanente com a obra de Wilhelm Reich e, assim, ninguém que tivesse sequer proposto algo semelhante ao movimento do sexpol. Reich não esteve presente na psicanálise renovada dos anos de 1960 e, se aparece na menção de Marie Langer de modo efêmero, parece ser mais por efeito do que como fonte da ruptura. Em todo caso, o autor de Psicologia de massas do fascismo vinha substituir Politzer como uma figura que poderia cumprir ao mesmo tempo com o imperativo político e com a reivindicação da psicanálise como disciplina associada ao impulso da revolução. 
Os problemas teóricos, intelectuais e políticos da relação entre marxismo e psicanálise haviam sido colocados de modo muito diferente por José Bleger num artigo de 1962, reproduzido em Cuestionamos ${ }^{11}$. A visada epistemológica blegeriana antecipava-se em refutar a perspectiva de uma integração de marxismo e psicanálise como "ciências complementares", ao manter uma distinção entre a psicanálise como um campo científico particular e o marxismo como uma "concepção unitária do mundo", razão pela qual denunciava como um erro a comparação em pé de igualdade. Com isso mantinha uma postura consistente com a que adotara em sua obra de 1958 e com os argumentos que expôs ao longo da polêmica que antecedeu sua separação do PC. Bleger foi notavelmente coerente em seu pensamento sobre esse ponto ao longo de quinze anos, como demonstram suas intervenções numa mesa-redonda, em 1965, em que polemiza com León Rozitchner e Antonio Caparrós (cf. Vários, 1969; Vezzetti, 2004).

Na passagem da década de 1960 para a de 1970, algo permanecia e algo mudava profundamente na trama das relações da psicanálise com o campo intelectual. Persistia como um legado o projeto de transformação da herança freudiana com vistas à mudança social, sintetizada na obra de Bleger do começo dos anos de 1960. Mas mudava a agenda, na medida em que o motivo maior da revolução impunha outra configuração imaginária e discursiva. O conflito havia irrompido no espaço mesmo que Bleger contribuíra para construir, fora da APA, na cátedra de Psicologia. Ali, na nova esquerda universitária, combinavam-se diversos componentes: o impacto ideológico da revolução cubana e uma renovação do marxismo que avançava, inexorável, por fora da ortodoxia do PC. Bleger, que havia sofrido precocemente a censura do Partido em nome dos dogmas do stalinismo, será contestado na universidade, desde meados dos anos de 1960, pela nova configuração ideológica revolucionária.

Nem Bleger nem Pichon Rivière acompanharam os renunciantes da APA, ainda que de algum modo tenham sido incluídos por Langer, que os menciona no prólogo de Cuestionamos. Pichon estava doente e não havia participado do processo; quanto a Bleger, a anedota é conhecida: na noite da renúncia esperaram em vão, até a madrugada, que se somasse aos renunciantes. Se Bleger elegeu permanecer na APA, a partir do artigo de 1962 é possível entender as razôes. E o fato de ser incluído em Cuestionamos, além de mostrar que seu reconhecimento intelectual e ideológico superava a separação que seria imposta pela ruptura, fazia emergir um problema que estava, em geral, ausente do conjunto das intervençôes: o que se arriscava per-
11. Ver Bleger (1962), também reproduzido em Langer (1971). 
12. Bleger morreu em 1972. Num trabalho póstumo, que não sabemos se tinha intenção de publicar, refere-se muito criticamente à ruptura. Ver Bleger (1973).

13. Rozitchner dirigiu o seminário "Freud e Marx", entre 1964 e 1966; também começou nesses anos grupos de estudo privados que se incrementaram depois da intervenção na universidade. der de Freud com uma atribuição demasiado compacta ao marxismo como sistema de pensamento e de crenças. De todo modo, fica pendente uma investigação em profundidade da posição de Bleger, as discussões com que acompanhou a fratura e a estreita relação posterior que manteve com muitos dos que se foram ${ }^{12}$. Langer havia anunciado, em seu trabalho em Viena, que agora não iria renunciar nem à psicanálise nem ao marxismo; numa intervenção póstuma, Bleger parece responder-lhe, sem nomeá-la, quando assinala que, na separação entre psicanálise e marxismo, "deu-se uma polarização no outro extremo: um retorno ao marxismo ou à esquerda coincide com um abandono e uma renúncia à psicanálise” (Bleger, 1973, p. 526).

\section{A universidade e a militância}

Vários dos renunciantes haviam acompanhado Bleger na carreira de Psicologia, entre 1960 e 1966. Ali, na Universidade de Buenos Aires, desenvolvera-se o maior experimento de "desinstitucionalização" da psicanálise e Bleger tinha sido seu promotor mais destacado. Desde seu ingresso como professor, com apoio estudantil, havia estabelecido as coordenadas de um projeto de extensão (e ao mesmo tempo de revisão) da psicanálise que buscava uma dupla legitimação: de um lado, a legitimidade de uma inscrição acadêmica, na Faculdade de Filosofia e Letras; de outro, uma nova legitimidade social para uma psicanálise orientada à abordagem dos problemas de saúde mental pública em estreito contato com as ciências sociais, baseadas na mesma sede acadêmica. A Faculdade e suas adjacências haviam sido o espaço dessa configuração discursiva e suas transformações. Também foram o espaço de um encontro entre Marx e Freud a cargo de León Rozitchner, uma iniciativa de estudo e formação autônoma diferente da de Bleger ${ }^{13}$. Emilio de Ipola testemunha os encontros e desencontros que se produzem no ambiente da Filosofia e Letras entre Rozitchner, Oacar Masotta e Raúl Sciarretta: entre eles cruzam-se diversas recepções (Sartre, Merleau-Ponty, Marx e, logo, Lévi-Strauss e Althusser) e os três cumprirão um papel decisivo na fisionomia da nova psicanálise nas duas décadas seguintes (cf. Ipola, 2001).

Detenho-me no panorama da Faculdade de Filosofia e Letras porque de lá, e de seus prolongamentos nos grupos de estudo que se consolidaram fora dela depois de 1966, vão emergir os novos mestres formadores dos psicanalistas dissidentes, sobretudo os já mencionados Rozitchner e Sciarretta. A ascensão de sua docência se produz paralelamente ao declínio da 
estrela de Bleger. A Faculdade foi, também, o espaço do encontro da nova sensibilidade de esquerda com as visões de um peronismo reconvertido, através do exemplo cubano, à causa da revolução. Kesselman dá conta de um itinerário ilustrativo do caminho que fizeram outros: considerado um dos "delfins" de Bleger (o outro era Bauleo), com quem se formara na APA, analisado por Marie Langer, havia se incorporado muito cedo à experiência de Goldenberg no Hospital de Lanús e à carreira de Psicologia, num curso ministrado pelo mesmo Goldenberg. Durante vários anos, formou-se simultaneamente com Bleger e com Rozitchner, até que entrou em contato com William Cooke e com os pensadores nacionais (Juan José Hernández Arreghi, Arturo Jauretche etc.), comprometeu-se com a CGT dos argentinos e com uma militância local que levou à incorporação na Juventude Peronista ${ }^{14}$.

O golpe de 1966 e a intervenção violenta na universidade, conhecida como a "noite dos bastões largos", puseram um final abrupto ao projeto de uma nova reconfiguração da psicanálise a partir do espaço universitário e com um horizonte de extensão à sociedade. Parecia o encerramento das saídas reformistas e marcou o começo do ocaso de Bleger, que já vinha sendo questionado pelos psicólogos que tinham se formado com ele. Os novos ares que varriam o campo intelectual e o discurso da filosofia e das ciências sociais, englobados um pouco abusivamente sob o rótulo do estruturalismo, implantavam novas ortodoxias, distanciadas do pluralismo que caracterizara a docência de Pichon Rivière e a obra de Bleger. E atacavam essa empresa nos dois terrenos que Bleger havia posto em relação, o marxismo e a psicanálise: Althusser e Lacan eram os emblemas do novo que pretendia liquidar as correntes humanistas e as abordagens fenomenológicas que haviam dominado essa trama de leituras e de relações entre a filosofia, a psicanálise e as ciências sociais.

Para uma história, que aqui só posso esboçar, da radicalização esquerdista dos psicanalistas, não basta assinalar as condições mais gerais da sociedade nem as transformaçôes ideológicas que se produziram nas figuras mais conhecidas, sobretudo Langer e Rodrigué. De um lado, se faz necessária uma visada mais colada às vicissitudes desse círculo nucleado em Bleger. Com ele haviam se formado em psicanálise e se iniciado no marxismo (numa atividade que em parte havia sido paralela ao currículo da APA) e com ele haviam participado da experiência docente desligada da universidade. Ademais, na formação do complexo discursivo que habilitava as relaçôes com a política e com a cultura intelectual da nova esquerda, deve-se considerar o
14. H. Kesselman, entrevista pessoal, 29 de junho de 2009. 
15. Langer (1971, p. 14) menciona apenas a Sciarretta no "Prólogo".

16. Rafael Paz, entrevista pessoal, 2 de junho de 2009. papel desempenhado por Rozitchner e Sciarretta, que tiveram em seus grupos de estudo vários dos renunciantes de $1971^{15}$. O golpe de 1966 parecia dinamitar as ilusões de quem pensava, a partir do trabalho na universidade, que era possível uma via gradual, reformista, de compromisso entre a mudança social e a agenda política da esquerda. Para muitos, a irrupção da ditadura era a confirmação de uma verdade que já estava instalada no discurso dos núcleos revolucionários: barrado o programa de uma mudança social e política pacífica, o que se instalava, depois de Cuba, era o imaginário da revolução e a opção pela luta armada. Essa reorientação na sensibilidade das esquerdas, que incluía o peronismo universitário, vai consolidarse e estender-se no clima aberto com o Cordobazo e a crise do regime que desembocou na destituição de Onganía.

A primeira renúncia pública, que envolveu vários dos psicanalistas críticos, produziu-se, então, na Faculdade de Filosofia e Letras, depois da "noite dos bastões largos". No entanto, para Bleger, que nunca cedeu às tentações do voluntarismo revolucionário, não desaparecia o objetivo de manter um programa de formação e investigação aberto aos estudantes e aos jovens graduados. Por volta de 1968, já fora da universidade, reuniu num grupo de estudos sobre psicanálise e marxismo vários dos psicanalistas que formarão um núcleo ativo dos renunciantes (Bauleo, Kesselman, Rafael Paz, Gregorio Baremblitt, Miguel Matraj, Eduardo Pavlovsky, entre outros); daí surgiu a iniciativa, finalmente frustrada, de formar um Instituto de Psicologia Social ${ }^{16}$. No final dos anos de 1960 aprofundava-se uma radicalização que adotava uma forma precisa: "militantização" que se cumpria diversa mas convergentemente em vários dos protagonistas e que cada vez mais iria fazer prevalecer a razão política sobre a lógica específica da disciplina. Bleger ficava deslocado nesse curso de ação. Em pouco tempo, vários (como já se expôs no caso de Kesselman) dedicaram-se a um compromisso militante com as organizações da nova esquerda. Segue um exemplo da superposição de práticas e de espaços, entre a saúde mental e a militância: Carlos Olmedo, um dos fundadores das Forças Armadas Revolucionárias (FAR), casado com Isabel Goldenberg, filha de Mauricio, trabalhava no Hospital de Lanús, na equipe do Programa de Psiquiatria Comunitária dirigida por Kesselman. Olmedo, Antonio Caparrós (ex-psiquiatra do PC e professor na carreira de Psicologia), Roberto Quieto e outros formaram, na Faculdade de Filosofia e Letras, em 1966 e antes do golpe de Onganía, um grupo de apoio à guerrilha do Che na Bolívia. Em fins desse ano, viajaram a Cuba para receber instrução militar, mas o projeto foi frustrado pela morte do 
Che, e o grupo decidiu organizar-se como uma guerrilha urbana, as FAR, que começou a atuar em $1969^{17}$.

No grupo Plataforma, então, ainda que nem todos tivessem uma relação direta com as organizaçôes revolucionárias, existia essa vontade de uma definição militante do compromisso político ${ }^{18}$. Ali residia o fundamento de uma luta que não podia reduzir-se nem à crítica das ideias nem à busca de reformas dentro da instituição. O horizonte era a transformação revolucionária da sociedade e o núcleo duro do compromisso se punha à prova na posição geral favorável à via armada. Essa é a configuração ideológica que se precipita nesses anos: um apego à eficácia direta da ação encarnada nas organizações armadas e que exercia uma indubitável fascinação sobre muitos que, ainda que não dispostos a pegar em armas, reconheciam a superioridade heroica do combatente, a partir do modelo do Che. Nos grupos intelectuais e profissionais, em geral alheios às rotinas de uma ação política mais tradicional, impunha-se a atração pelo que aparecia como a eficácia imediata dos operativos, o dano produzido ao inimigo e o apoio (ao menos até o chamado de eleiçôes em 1972) de setores populares. Ainda que não haja casos conhecidos de psicanalistas incorporados à ação guerrilheira, o que se consolidava era o padrão de um curso imposto por uma vanguarda decidida, uma espécie de "foquismo desarmado", para usar a expressão que Ruben Caletti cunhou para essa configuração revolucionária ${ }^{19}$.

Claramente, mudava a ideia mesma do compromisso em relação aos parâmetros do primeiro Sartre. É o que se pode ver numa entrevista publicada em Nuevo Hombre, a revista do peronismo revolucionário, em agosto de 1971: o velho farol da intelectualidade crítica já não é aquele que ingressava nas revistas literárias dos anos de 1960 ou nas análises de Masotta sobre Roberto Arlt. Sartre se reunia com Fanon, anunciava uma situação revolucionária e se desculpava porque, aos 65 anos, a opção pelas armas não estava a seu alcance ${ }^{20}$. Paradoxalmente, nessa reconfiguração do sartrismo para os motivos da revolução no Terceiro Mundo, era dominante um forte componente anti-intelectual que acabou impondo um selo à radicalização da nova esquerda.

\section{Psicanalistas e psiquiatras}

A recuperação do acontecimento, a ruptura de 1971, ficou em grande medida fixada pelo testemunho de seus protagonistas mais destacados, sobretudo Marie Langer e Emilio Rodrigué. Nesse resgate o que se reitera é a
17. Sobre a presença de $\mathrm{Ol}-$ medo como "assessor epistemológico" da equipe de Psiquiatria Comunitária em Lanús, ver Carpintero e Vainer (2004, p. 106 e nota 45, p. 110) e as biografias de Olmedo e de Quieto em Tarcus (2007, pp. 466-468 e 539541). As FAR iniciaram suas operações em junho de 1969 , com o incêndio de treze supermercados Minimax em Buenos Aires, em repúdio à visita de Nelson Rockefeller. Essa ação não foi assumida pela organização, que se deu a conhecer publicamente com a tomada de Garin em julho de 1970. Olmedo morreu num enfrentamento em 3 de novembro de 1971, a mesma noite em que se decidia e se assumia a renúncia coletiva da APA, que foi apresentada no dia seguinte.

18. O tópico da militância dos psicanalistas dissidentes é um dos temas pendentes desta investigação.

19. Ocupo-me do tema em Vezzetti (2009, caps. 2 e 3).

20. "Sartre habla", entrevista com John Gerassi, Nuevo Hombre, n. 4, 11-17 de agosto de 1971 . 
experiência de um verdadeiro descobrimento da política a partir do impacto da luta popular de 1969. O Cordobazo havia operado como despertador de uma consciência social e política que permanecia, na percepção de seus próprios atores, adormecida. É fácil remeter essa correspondência às mudanças no clima político coletivo: 1969 aparecia como o marco de um novo ciclo que acabava de fechar o período aberto em fins dos anos de 1950. Nele se conjugava o impacto convulsivo do conflito social de massas com a função imaginária das lutas, sobretudo estudantis, que se estendiam pelo mundo. Na verdade, levando em conta que o impulso que desembocou na criação do primeiro grupo dissidente argentino nasce em Roma, nesse mesmo ano, com o movimento Plataforma internacional, percebe-se que a rebelião dos psicanalistas pode ser considerada tanto filha das lutas sociais cordobenses como dos ecos europeus do maio francês.

No plano local, para que as lutas sociais se introduzissem no mundo reservado dos psicanalistas, foi necessária a experiência de participação na Federação Argentina de Psiquiatras (FAP), em Buenos Aires, que foi destacada pelos mesmos protagonistas como um verdadeiro rito de passagem do interior fechado da associação para o espaço político público:

Ali pudemos adquirir, nós, psicanalistas de alta categoria, "rua" num sentido político [...]. Estávamos juntos futuros membros de Plataforma e Documento com psiquiatras comunistas e outros, pertencentes a pequenos grupos esquerdistas, e psicanalistas “independentes” (Langer, 1971, p. 18).

A vontade de ação de alguns dos protagonistas da ruptura havia encontrado um espaço de realização. A FAP surgira em 1959 no período de reformas da assistência e da organização profissional posterior à queda do peronismo. Nucleava psiquiatras de orientações muito diversas, não só os professores das cátedras e os responsáveis pelos hospitais psiquiátricos, mas também alguns psicanalistas, como Pichon e Bleger, que participavam dos congressos periódicos realizados pela organização. Um núcleo de psiquiatras comunistas constituía um polo ativo da instituição e até fins dos anos de 1960 vários psicanalistas começaram a atuar na seção da capital: Bauleo e Kesselman foram vogais desde 1968 e Rodrigué foi eleito presidente em 1969 (cf. Carpintero e Vainer, 2004, p. 35). Este último chegava ao cargo de forma inesperada, sem haver atuado previamente na entidade. Gervasio Paz, psiquiatra membro do grupo comunista, então presidente da FAP em nível nacional, ofereceu-lhe o cargo e fez os arranjos para que fosse eleito. 
Rodrigué admite que não sabia muito bem o que era essa instituição e acrescenta que ali sua vida começou a tomar um "rumo ideológico determinado por outros" (Rodrigué, 2000, p. 115). Rodrigué havia começado a converter-se em uma figura pública, presente na mídia e com perfil de escritor a partir de sua novela Heroína, um best-seller publicado nesse mesmo ano ${ }^{21}$. Marie Langer será presidenta da FAP Nacional em 1972. De modo que os psicanalistas mais velhos do grupo dissidente chegaram à FAP, o meio externo que lhes havia permitido sair do enclausuramento na APA e comunicarse com a política, pela mão do PC. Nos compromissos que assumiram não houve, então, muita "rua", se pelo termo se entende uma militância associada a práticas políticas em frentes de massas. Essa experiência (e essa visão da política) parece ter sido trazida pelos membros mais jovens. Questionando a cena mais de perto, o que se percebe nos mais velhos é que o deslocamento para a política é menos um efeito de descobrimento que de arrasto e cooptação: um "rumo ideológico determinado pelos outros", para reiterar a expressão usada por Rodrigué.

Cabe uma primeira observação a respeito das posições dos comunistas argentinos. Em menos de dez anos, desde os tempos da expulsão de Bleger, mudou o seu juízo sobre a psicanálise, ou ao menos sobre os psicanalistas, agora considerados aliados no trabalho que vinham desenvolvendo no campo da saúde mental. Esse trabalho político-sindical torna-se manifesto com o convite para visitar a URSS, que se efetiva numa delegação de psicanalistas que se incorporaram à FAP. Entre outros, viajam Langer, Rodrigué (que deixou testemunhos escritos dessa viagem), Bauleo, Pavlovsky, Ulloa, Diego e Giolu García Reinoso ${ }^{22}$. O abismo doutrinário que havia levado à denúncia inflamada da psicanálise como uma peste burguesa acentuou-se num tempo em que as figuras maiores dessa guerra contra o freudismo parecem ter entrado no ocaso. Por outro lado, o velho partido stalinista vinha perdendo presença e prestígio na relação com o mundo intelectual: em 1963 separava-se o grupo que editava Passado e Presente, em Córdoba; em 1968, perdia a maior parte da juventude, que passou a formar o Partido Comunista Revolucionário (PCR), com uma orientação inicialmente guevarista, e alguns psiquiatras jovens da nova organização formaram um agrupamento paramilitar na FAP Capital. No campo psiquiátrico e nas relações com o mundo "psi", foram relegadas as figuras que dominaram a década anterior: Jorge Thénon e César Cabral. O pavlovismo estava em retirada e consequentemente parecia possível, para alguns ao menos, uma relação mais aberta com a psicanálise. Nesses anos, alguns psiquiatras do PC entraram
21. O romance é de 1969 e foi um best-seller, em 1972 foi feito o filme dirigido por Raúl de la Torre, com roteiro de Rodriguée Dela Torre. Rodriguéatuava no filme junto com Graciela Borges, Eduardo Pavlovsky e Lautaro Murúa.

22. Rodrigué refere-se à viagem em duas de suas obras autobiográficas: Rodrigué e Berlin (1977) e Rodrigué (2000). Uma breve crônica da visita, que incluía psiquiatras, psicanalistas e psicólogos argentinos e uruguaios, encontra-se em Golder e Gonzáles (2006, pp. 124-126). 
23. Sobre a decisão de Paz de entrar na APA, ver Carpintero e Vainer (2004, p. 47). De acordo com o testemunho de Juan Carlos Volnovich, Paz fazia análise com Langer e Antonio Caparrós com Ulloa; ver Idem, p. 175.

24. O episódio, entre patético e desopilante, é narrado duas vezes, em Rodrigué (1977, pp. 12-15) e Rodrigué (2000, pp. 142-149).

25. Ver o testemunho de Langer (1981, p. 102). Uma versão transcrita do encontro com Bassin está em Golder e Gonzáles (2006). Agradeço a Luciano García por me dar a conhecer e disponibilizar essa fonte.

26. Ver Bleger (1968a). O artigo havia sido publicado em Nueva Sión, Buenos Aires, em 1963; não pude consultar o número correspondente. Para alguns, essa crítica de Bleger foi o motivo determinante de sua separação do PC. Ver Dagfal (2009, p. 345). em análise. A mudança era tardia; o desencontro com os novos tempos ficava demonstrado palpavelmente pelo testemunho de Gervasio Paz, que estivera estreitamente ligado à corrente pavloviana dirigida por Thénon: a ruptura dos psicanalistas com a organização não só o tomou de surpresa como então ele, que começara a fazer análise com Langer, havia decidido ingressar na $\mathrm{APA}^{23}$.

$\mathrm{O}$ ativismo do velho partido soviético na nova relação com os psicanalistas, que se intensificava nesses anos, foi não só tardio como pouco eficaz, levando em conta os resultados da viagem à URSS e aos países do socialismo real: a experiência não levou a um incremento da influência do partido. Se, como disse um dos convidados, esperavam afiliá-los, só conseguiram a adesão efêmera de Rodrigué, que a assinou em estado de embriaguez e depois se arrependeu ${ }^{24}$. A visita foi programada com todo esmero pelos anfitriōes. Mostravam-se interessados em discutir as relações possíveis da psicanálise com a ciência psicológica soviética: houve encontros na Faculdade de Psicologia da Universidade de Moscou, acompanharam aulas de Alexander Luria e Alexis Leontiev, a pedido do grupo visitante, tiveram um encontro com Filipp Bassin, que havia publicado um livro sobre o problema do inconsciente ${ }^{25}$. Marie Langer aparece como a mais comprometida nesse encontro possível da psicanálise com a psicologia soviética. Foi sua a iniciativa da reunião com Bassin; de pronto fez traduzir e publicou seu livro sobre o inconsciente, para o qual escreveu um prólogo em que mostrava seu interesse em explorar as convergências possíveis com a psicanálise. Mas as questões que formulava, em 1972, não eram só teóricas ou doutrinárias; interrogava-se também sobre o lugar da psicanálise num regime socialista que considerava iminente na Argentina e que não concebia que pudesse ser distinto daquilo que o modelo soviético mostrava (cf. Langer, 1972; Golder e Gonzáles, 2006, pp. 143-146).

Langer, numa evocação retrospectiva, questiona que os cientistas e os psiquiatras soviéticos não admitissem a psicanálise, mas elogia o serviço de socioterapia no hospital psiquiátrico de Moscou (cf. Langer, 1981, p. 102). Em 1968, os tanques soviéticos haviam entrado em Praga; até 1971, seriam conhecidas as primeiras denúncias sobre o uso do dispositivo psiquiátrico na repressão dos dissidentes e o conflito sino-soviético estava em seu ponto máximo. José Bleger havia protagonizado, quase dez anos antes, uma visita muito diferente e sumamente crítica: preocupado com a situação dos judeus, havia denunciado o antissemitismo na pátria de Lênin e Stalin ${ }^{26}$. Nenhum desses problemas parece ter estado entre as preocupaçōes de Langer, 
nem dos psicanalistas de esquerda que visitaram a URSS. Nesses anos, na Argentina (como na Europa), as entonações dominantes na configuração da nova esquerda rompiam com a hegemonia soviética. Como se disse, o PC havia perdido sua liderança intelectual e política e seu programa reformista recebia os questionamentos cruzados das novas tendências revolucionárias na esquerda e no peronismo. Esse processo acentuou-se na época em que Langer oferece seu testemunho, por volta de 1980. No entanto, na evocação retrospectiva da visita, assim como em suas expressões públicas, manteve-se fiel à linha soviética (alinhada com as posiçôes cubanas): nem as denúncias sobre o "socialismo real", nem a crise do modelo soviético na nova esquerda, nem o antissemitismo na URSS figuram como problemas.

Rodrigué evoca a viagem no registro da paródia. É evidente que não tem nenhuma simpatia pelo experimento soviético na era Brezhnev. Mas o modo mais desafiador que encontra para demonstrá-lo é fumar marijuana diante das muralhas do Kremlin. A outra anedota destacada da viagem é o episódio já mencionado, na visita a uma bodega na Bulgária, em que "um órfão do PC argentino", que não identifica, se aproveita de seu estado passageiro de embriaguez para filiá-lo ao partido (cf. Rodrigué 1977, pp. 14 e 40). Por outro lado, não há em seus muitos escritos de memorialista interrogaçōes ou juízos retrospectivos sobre os problemas conceituais ou políticos da relação da psicanálise com o marxismo, ou com as posições políticas da esquerda. Em sua rota, que sempre aparece determinada pelas ações dos outros, aceitou depois filiar-se ao peronismo, convencido pela insistência de Kesselman; e deixou o testemunho de uma insólita coluna psicanalítica que, em 1973, marchou para Ezeiza para receber o general Perón ${ }^{27}$. Durante o breve governo de Cámpora, Langer e vários dos renunciantes incorporaram-se à universidade, pelas mãos do peronismo montonero, na cátedra de Psicologia Médica, a cargo de Kesselman.

Finale

Nas reconstruções ou nos testemunhos sobre a ruptura e suas consequências, quase sempre se pôs o foco nas primeiras figuras do elenco psicanalítico, notadamente Langer e Rodrigué. Mas do exposto até aqui (incluindo a retomada dos testemunhos) se depreendem as características e os limites da politização que os envolvia. A política quase sempre vem de fora: o Cordobazo, os convites de militantes do PC ou do peronismo, a FAP, a Plataforma Internacional etc. Rodrigué oferece uma versão extrema
27. Também esse evento é contado duas vezes: ver Rodrigué (1977, pp. 16-17; 2000, pp. 149 e 152-154). Marie Langer ia à frente da pequena coluna da FAP. 
e paródica dessa relação externa com a política. Mas também Gilou García Reinoso disse que a decisão da ruptura "foi imposta por alguns dentro de Plataforma”: provavelmente tratava-se do núcleo radicalizado que Kesselman e Bauleo encabeçavam (cf. Carpintero e Vainer, 2004, p. 43). A disposição anti-institucional estava na sensibilidade da época, mas não necessariamente devia conduzir ao cisma: Pichon Rivière ou Bleger haviam mostrado que era possível trabalhar fora da APA, voltado à sociedade, sem necessidade de romper com a organização. Para que se instale o ânimo de ruptura será necessário que a razão política, sob a forma dominante de uma vontade revolucionária, imponha a lógica da guerra sobre os conflitos do setor. Como se viu, o referente maior desse relevo épico da política, como transformação violenta, que penetra e altera o sistema de relações nas instituiçôes, foi o Cordobazo. Mas dado que a revolta em Córdoba se erigia simultaneamente em emblema e marca unificante no discurso e nas ações da nova esquerda, como consequência, no mesmo movimento em que o núcleo psicanalítico dissidente buscava afiliar-se ao movimento político de massas, enfrentava o risco de relegar o objeto e a razão de sua disciplina. O fantasma da luta total impunha sua lógica por cima das diferenças na natureza dos conflitos (teóricos, políticos, institucionais, de formação) que convergiam para o campo psicanalítico e se encarnava no significante princeps que apontaria para a restituição de uma identidade político-social: trabalhadores da saúde mental. César Cabral, velho militante do PC, numa carta a Rodrigué, assinalava a incongruência desse deslocamento imaginário. Nela referia-se ao projeto de criação da Federação dos Trabalhadores de Saúde Mental (que finalmente se chamou Coordenadoria) e assinalava a ausência dos verdadeiros trabalhadores, o pessoal de enfermaria. Na verdade, questionava o ultraesquerdismo do empreendimento. De um lado, sublinhava que encarar uma coordenação "das lutas de psiquiatras, psicólogos, assistentes sociais, psicopedagogos, enfermeiros, não supõe necessariamente agrupá-los numa organização única”. Expunha o risco de marginalizar os que não estivessem à altura do "grau de

28. César Cabral, carta a Emilio Rodrigué, 14 de janeiro de 1972 (arquivo pessoal). Agradeço a Roberto Harari, que a colocou a minha disposição faz uns anos, como parte do material que conservava de sua gestão na Associação dos Psicólogos de Buenos Aires. consciência revolucionária dos promotores da nova organização”. E terminava expressando o temor de que "a Federação converta-se num brinquedo violento que esgote em teorizações revolucionárias abstratas o grande desejo de luta que a todos nos anima"28.

Uma história algo diferente da radicalização psicanalítica, que apenas começa a contar-se, torna-se possível quando se enfocam a posição e as açôes dos protagonistas mais jovens, comprometidos com uma prática mi- 
litante. Ali se destacam os cruzamentos entre a atividade profissional, a Faculdade de Filosofia e Letras, os novos espaços de intervenção pública no campo da saúde mental e as primeiras formas e redes da militância revolucionária. Isso começou antes do Cordobazo. Já se fez referência ao antecedente da mesa sobre "Ideologia e Psicologia Concreta", em 1965. Em outubro de 1968, no Terceiro Congresso Nacional de Psicologia em Rosário, pela primeira vez havia emergido uma divisão por motivos ideológicos, que levou à reunião do "Primeiro Encontro Paralelo para a Revisão Crítica da Psicologia" 29 . Armando Bauleo integrava a comissão formada a partir desse encontro. Ele e Kesselman escreviam nos Cuadernos de Psicología Concreta. Discípulos de Bleger, compartilharam a experiência universitária até 1966 e seguiram trajetórias diversas mas convergentes no processo de radicalização política. Bauleo havia deixado o PC, mas conservava uma identidade de esquerda marxista e militava na favela de Retiro. Kesselman militava na juventude peronista, em Berisso e Ensenada, e tomou parte na redação de Nuevo Hombre desde sua criação, em julho de 1971, junto com figuras conhecidas do peronismo revolucionário, como Dardo Cabo, Rodolfo Ortega Peña e Eduardo L. Duhalde ${ }^{30}$. Nessa rede de pertencimentos e de ações revela-se a nova sensibilidade e as formas da politização no espaço universitário e nas organizações da esquerda e do peronismo.

Com a exploração inicial das trajetórias de Bauleo e Kesselman, que não exclui o papel de outros integrantes dos grupos dissidentes, quis ilustrar o papel cumprido por essa trama menos visível no tremor ideológico que atingia o círculo da psicanálise. Ambos, como se disse, participaram das primeiras reuniões de Plataforma Internacional e impulsionaram o agrupamento local. Não é possível estender-me numa exploração desse contexto internacional, mas salta à vista que os temas que convocavam a esse agrupamento, integrado sobretudo por psiquiatras e psicanalistas suíços e italianos, girava em torno dos problemas da formação e das relações no interior das associações psicanalíticas: o rechaço ao autoritarismo, como no primeiro impulso do maio francês, aparecia como o disparador da contestação. Plataforma Internacional deixou de existir nos anos de 1980. A consequência mais importante de seu impulso crítico e dissidente foi a perda do monopólio da IPA sobre a administração da formação psicanalítica. Nas palavras de dois de seus fundadores, Berthold Rothschild e Marianna Bolko, "não há nenhuma necessidade de um training psicanalítico formalizado" (2008, p. 717). Em síntese, o que ficou é uma dupla impugnação: do artefato de poder disfarçado de programa de formação e aprendizagem e da ilusão de um
29. Ver Cuadernos de Psicologia Concreta, 1, 1969, p. 43.

30. Sobre o trabalho de Bauleo na favela de Retiro, ver Bauleo (1974, p. 2). O autor era, em 1965 e 1966, JTP da cátedra de Psicohigiene, a cargo de Bleger: Volnovich, um dos membros de Plataforma, foi um dos alunos e lembra que alguns trabalhos eram realizados nessa cidade, ver Volnovich (1992, p. 121). Sobre a militância de Kesselman, ver Carpintero e Vainer (2004, p. 106). 
31. Sobre o "homem novo", ver Vezzetti (2009, cap. 4). pertencimento que reforça ao mesmo tempo o reflexo de obediência e o isolamento autossuficiente.

Outro era o destino sonhado para o movimento contestatório argentino em 1971. Nesse ano, pouco antes da renúncia coletiva, Hernán Kesselman publicava em Nuevo Hombre um artigo sobre Plataforma Internacional. O contracongresso de Roma ficaria situado na esteira das grandes lutas europeias de 1968, mas também, numa associação algo forçada, na das rebelióes sociais de 1969 na Argentina (cf. Kesselman, 1971). Reivindicava o papel dos sul-americanos (os argentinos em particular) na orientação política que havia levado Plataforma Internacional ao segundo encontro em Viena, em 1971, que pleiteava o papel "da teoria e da prática psicanalítica à luz dos diferentes caminhos para o socialismo". O que se acentuava no todo, de acordo com a orientação da revista, era a necessidade de incluir as rebeldias dos psicanalistas críticos nas lutas anticapitalistas e anti-imperialistas dos povos do Terceiro Mundo. O horizonte projetado, então, não era o da reforma institucional, mas um compromisso que chegava até "a possibilidade de participar na criação coletiva do homem novo". Uma nova psicanálise requeria o homem novo na nova sociedade e só podia edificar-se no processo de uma revolução que devia cumprir-se no interior dos sujeitos ${ }^{31}$. O obstáculo maior, para Kesselman, localizava-se no "intelectualismo", só superável com a inclusão completa do psicanalista (do intelectual em geral) nas lutas dos explorados. No final, o artigo anunciava o fim de uma época e contrastava o dinamismo e a agitação do contracongresso com o silêncio e a imobilidade da reunião oficial, nos luxos e nos faustos do palácio Hofburg; e profetizava "o final definitivo, não já de um congresso internacional, nem da velha psicanálise, mas do velho, do caduco e do enfermo de todo um sistema”.

Em conclusão, situar as condições da fratura exige levar em conta a trama de mudanças que se desenvolve ao longo do período e indagar um conjunto variado de espaços, motivos e atores. Obviamente, não basta a reconstrução testemunhal de seus protagonistas. O selo político que a marcou, ao colocá-la sob o manto do marxismo e da esquerda política, sobrecarregou a recuperação do acontecido com a história posterior, aberta com a repressão e o terrorismo de Estado desatados sobre o setor. Trata-se de um capítulo essencial da história recente da psicanálise tanto quanto da história da cultura de esquerda na Argentina. O déficit historiográfico traduz sem dúvida as dificuldades para estabelecer um balanço desse passado a partir da situação atual de crise dessa fração intelectual e política. Finalmente, há mais de uma memória de esquerda, e na medida em que esse passado tende a ser posto em 
linha com as identidades e os alinhamentos do presente, como toda história, supõe algo de luta pelo sentido do sucedido - em um momento, de outro lado, em que as convicções e tradiçôes que alimentavam uma identidade de esquerda permanecem desarticuladas e em processo de revisão.

\section{Referências Bibliográficas}

BAUleO, A. (comp.). (1974), Los sintomas de la salud: psiquiatría social y psicohigiene. Buenos Aires, Cuarto Mundo.

Bleger, J. (1962), "Psicoanálisis y marxismo". Cuestiones de Filosofia, Buenos Aires, 1 (2): 60-73.

. (1968a), "Los judíos en la Unión Soviética” [1963]. In: VÁrIOS, Nacionalidad oprimida: la minoría judia en la URSS. Montevidéu, Mordejai Anilevich.

- (1968b), Psicoanálisis y dialéctica materialista. Buenos Aires, Paidós. . (1973), "La APA, el psicoanálisis y los psicoanalistas". Revista de Psicoanálisis, XXX, 2.

BolKo, Marianna \& RoTHSCHILD, Berthold. (2008), “Una 'pulce nell'orecchio'. Cronaca del controcongreso dell' International Psychoanalytic Association di Roma del 1969”. Psicoterapia e Scienze Umane, n. 6, XL, 3, p. 717.

Carpintero, Enrique \& VAiner, Alejandro. (2004), Las huellas de la memoria: psicoanálisis y salud mental en la Argentina de los 60 y 70. Buenos Aires, Topía, I.

Снама, Mauricio S. (1999), "La expansión de los límites de lo possible: el itinerario de una experiencia innovadora en la salud mental a fines de los 60". In: PuCIARELLI, Alfredo (ed.), La primacía de la politica. Lanusse, Perón y la Nueva Izquierda en tiempos del GAN. Buenos Aires, Eudeba.

Dagfal, A. (2009), Entre París y Buenos Aires: la invención del psicólogo (1942-1966). Buenos Aires, Paidós.

Documento. (1972), “Declaración del Grupo Documento”. Los Libros, 25, p. 6.

GOLDER, Mario \& GONZÁLEs, Alejandro. (2006), Freudy Vigotsky: inconsciente y lenguaje. Buenos Aires, Fundación de Investigaciones sociales y políticas, Ateneo Vigotskyano de la Argentina.

IpolA, Emilio de. (2001), “Mi amigo Leon”. Lote, 46, abril. Disponível também em http://fernandopeirone.com.ar/Lote/nro046/miamigo.htm.

Kesselman, H. (1971), "Plataforma internacional: psicoanálisis y antiimperialismo". Nuevo Hombre, ano 1, n. 6, pp. 25-31, ago.

LAnger, M. (1950), "El mito del 'niño asado”. Revista de Psicoanálisis, VII, n. 3. . (1951), "El mito del 'niño asado"”. In: Maternidad y sexo. Buenos Aires, Nova. 
. (1957), "El niño asado y otros mitos sobre Eva Perón”. In: , Fantasias eternas a la luz del psicoanálisis. Reedição ampliada. Buenos Aires, Nova [2a edição Hormé, 1966]. . (org.). (1971), Cuestionamos. Buenos Aires, Granica. . (1972), "Prólogo". In: BASsin, F. V. El problema del inconsciente. Buenos Aires, Granica.

Langer, M. et al. (1981), Memoria, historia y diálogo psicanalítico. México, Folios. NitzsCHKe, Bernd. (2003), "Psychoanalysis and national socialism: Banned or Brought into conformity? Break or continuity?”. International Forum of Psychoanalysis, 12, pp. 98-108. Disponível em http://www.werkblatt.at/nitzschke/text/nationalso cialism.html.

Plataforma. (1972), “Información del Grupo Plataforma”. Los Libros, 25, mar., p. 8. Plotkin, Mariano. (2003), Freud en las pampas. Buenos Aires, Sudamericana.

Rodrigué, E. (2000), El libro de las separaciones. Buenos Aires, Sudamericana.

Rodrigué E. \& Berlin, Martha. (1977), El anti-yo. Madri, Fundamentos.

TARCus, Horacio (org.). (2007), Diccionario biográfico de la izquierda argentina. Buenos Aires, Emecé.

TERÁN, O. (2006), "Entre la filosofía y la historia: un recorrido”. Entrevista realizada por Javier Trímboli e Roy Hora em 1994. In: , De utopías, catástrofes $y$ esperanzas. Buenos Aires, Siglo XXI.

UlLOA, F. (1971), "Extrapolación del encuadre analítico en el nivel institucional: su utilización ideológica y su ideologización”. In: LANGER, M. (org.), Cuestionamos. Buenos Aires, Granica, p. 109.

VÁRIOS. (1969), “Ideología y psicología concreta”. Cuadernos de Psicología Concreta, n. 1.

Vezzetti, H. (1991), "Psicoanálisis y cultura comunista: La querella de José Bleger”. La Ciudad Futura, n. 27, fev./mar. . (1995), "Isabel I, Lady Macbeth, Eva Perón”. Punto de Vista, n. 52, ago. . (2004), "Los comienzos de la psicología como disciplina universitaria y profesional: debates, herencias, proyecciones sobre la sociedad”. In: NeIBURG, Federico $\&$ Plotkin, Mariano (eds.), Intelectuales y expertos: la constitución del conocimiento social en la Argentina. Buenos Aires, Paidós.

(2009), Sobre la violencia revolucionaria. Memorias y olvidos. Buenos Aires, Siglo XXI.

Volnovich, J. C. (1992), "Bleger: la desgarrada soledad de un analista”. Diarios clínicos, n. 5, p. 121 . 


\section{Resumo}

Psicanálise e marxismo: a fratura da Associação Psicanalítica Argentina (1971)

$\mathrm{O}$ artigo aborda um acontecimento inusual em que se cruzam a história da psicanálise e a da esquerda marxista: a renúncia, por motivos ideológicos, de dois grupos à associação argentina. $\mathrm{O}$ trabalho procura ir além do testemunho dos protagonistas e interrogar os relatos fixados sobre o acontecimento. Para isso explora, a partir dos anos de 1960, as condições e as alternativas desse encontro entre Freud e Marx, particularmente no âmbito universitário (a Faculdade de Filosofia e Letras da UBA), na organização corporativa profissional (a Federação Argentina de Psiquiatras) e em organizações políticas da época (o Partido Comunista e o peronismo revolucionário).

Palavras-chave: Psicanálise; Marxismo; Esquerda; Peronismo; Argentina.

\section{Abstract}

Psychoanalysis and Marxism: the splitting of the Argentine Psychoanalytic Association (1971)

The article looks at an unusual event in which the history of psychoanalysis and that of the Marxist left intersected: the resignation of two groups from the Argentine association on ideological grounds. Looking to go beyond the testimony of the protagonists and interrogate the accounts focusing on the event, the text explores the conditions and alternatives of this encounter between Freud and Marx from the 1960s onwards, particularly in academia (the Faculty of Philosophy and Letters of the UBA), in a professional organization (the Argentine Federation of Psychiatrists) and in political organizations active during the period (the Communist Party and revolutionary Peronism).

Keywords: Psychoanalysis; Marxism; Left; Peronism; Argentina.

Texto recebido e aprovado em 15/7/2009.

Hugo Vezzetti é professor da Universidade de Buenos Aires e pesquisador do Conicet. É autor de Pasado y presente. Guerra, dictadura y sociedad en la Argentina. Email: hugo.vezzetti@gmail. com. 